Phosphorus Research Bulletin Vol. 34 (2018) pp. 014-018

\title{
PREPARATION OF NOVEL CERIUM PHOSPHATE WHITE PIGMENT
}

\author{
Hiroaki ONODA ${ }^{1 *}$, Haruka MURAKI ${ }^{1}$ \\ (*Corresponding author: onoda@kpu.ac.jp) \\ ${ }^{1}$ Department of Informatics and Environmental Sciences, Kyoto Prefectural University, \\ 1-5, Shimogamo Nakaragi-cyo, Sakyo-ku, Kyoto 606-8522, Japan
}

Keywords: white pigment, cerium phosphates, powders

\begin{abstract}
Catalytically active cerium dioxide is used as light reflection materials for cosmetic applications. Therefore, cosmetics containing this pigment cause oxidation of the skin. From this fact, the substitute for cerium dioxide is required to prepare the cosmetics without catalytic activity. Herein, as novel white pigments for use in cosmetics, cerium phosphate was prepared at various $\mathrm{pH}$ values. The chemical composition, powder properties, catalytic activity, color, and smoothness of the cerium phosphate were evaluated. All samples prepared in this work indicated XRD pattern of the cerium phosphate hydrate. The sample prepared at $\mathrm{pH} 4$ had relatively small particles and low static friction resistance. The samples prepared at $\mathrm{pH} 5,6$, and 7 had no photocatalytic activity. The samples prepared at pH 5 and 6 exhibited high reflectance within the range of visible light.
\end{abstract}

(Received Nov 20, 2018; Accepted Dec 17, 2018)

\section{INTRODUCTION}

Titanium dioxide and zinc oxide are used as white pigments for cosmetic applications ${ }^{1}$. These oxides are known to be photocatalytically active; therefore, cosmetics containing these pigments cause decomposition of a certain amount of sebum on the skin under ultraviolet radiation in sunlight ${ }^{2,3}$. In our previous works, titanium and zinc phosphates without photocatalytic activity were prepared as novel white pigments for cosmetics ${ }^{4,5}$. These compounds have a possibility to replace titanium dioxide and zinc oxide with photocatalytic activity. On the other hand, cerium dioxide is also used as light reflection materials for cosmetic applications. This oxide is known to be oxidation catalysts; therefore, cosmetics containing this pigment too much cause oxidation of the skin under ${ }^{6,7}$. The substitute for cerium dioxide is required to prepare the cosmetics without catalytic activity.

Phosphates have been used as ceramic materials, catalysts, fluorescent materials, dielectric substances, metal-surface treatments, detergents, food additives, in fuel cells, as pigments, and so on ${ }^{8-11}$. Phosphate materials are recognized to have high biocompatibility and are therefore expected to be useful as white pigments in cosmetics ${ }^{12,13}$. White pigments without oxidation active are required for skin protection during cosmetic use. The moisture retention of the materials used in cosmetics is also important for preventing dry skin. Because phosphates are hydrophilic materials, the phosphate pigments are suitable to use for cosmetics from this viewpoint.

The particle shape and size distribution of the phosphates are important parameters for cosmetic pigment application ${ }^{14}$. Spherical, homogenous particles are expected to spread well on the skin. However, overly small particles are unsuitable because the pigments may enter the pores of the skin. Generally, the pigments with sub-micrometer dimensions are used in cosmetic applications.

In this study, to obtain a novel white pigment without the catalytic activity, cerium phosphate was prepared at various $\mathrm{pH}$ values. The respective chemical compositions, powder properties, photocatalytic activity, color, and smoothness of the obtained precipitates were studied for application to the pigments for cosmetics.

\section{EXPERIMENTAL}

Cerium nitrate solution $\left(0.5 \mathrm{~mol} \cdot \mathrm{L}^{-1}\right)$ was mixed with phosphoric acid $\left(0.5 \mathrm{~mol} \cdot \mathrm{L}^{-1}\right)$ in a molar ratio of $\mathrm{P} / \mathrm{Ce}=1 / 1$ at room temperature for more than 1 hour. And then, the mixed solutions were adjusted to $\mathrm{pH} 4$, 5,6 , and 7 with sodium hydroxide solution. The precipitates were then filtered, washed with water, and dried at room temperature over 3 days $^{5}$. For comparison, samples were also prepared without $\mathrm{pH}$ 
adjustment ( $\mathrm{pH} 1)$. All chemicals were commercial purity and were acquired from Wako Chemical Industries Ltd. (Osaka Japan) and used without further purification.

The crystalline phase of these materials was analyzed using X-ray diffraction (XRD; MiniFlex; Rigaku Corp., Tokyo, Japan) with monochromated $\mathrm{Cu}-\mathrm{K} \alpha$ radiation. The IR spectra of the materials were recorded on a HORIBA FT-IR 720 (Horiba Ltd., Kyoto, Japan) using the $\mathrm{KBr}$ disk method.

The shapes and sizes of the particles comprising the precipitates were estimated from the scanning electron microscopy (SEM; instrument: JSM-5510LV; JEOL Ltd., Tokyo, Japan) images and particle size distributions. The particle size distributions of these materials were measured using a centrifugal precipitation particle-size distribution analysis system (SA-CP3L, Shimadzu Corp., Kyoto, Japan).

The cosmetic properties of the developed precipitates were estimated by analysis of the color phase, photocatalytic activity, and smoothness. The color of the phosphate pigments was estimated using ultraviolet-visible (UV-Vis) reflectance spectra acquired with a UV2100, Shimadzu Corporation instrument (Kyoto, Japan) (reference compound: $\left.\mathrm{BaSO}_{4}\right)$. The color of materials was also estimated with a TES135 plus color analyzer (TES Electrical Electronic Corp, Taipei, Taiwan). The $\mathrm{L}^{*}$ value means the whiteness of the powder, in which 100 is white, on the opposite site 0 is black. The $a^{*}$ value means the red of the powder, with positive (maximum; +60) and negative (-60) values are corresponding with red and green, respectively. The $\mathrm{b}^{*}$ value indicates the yellow, in which positive (maximum; +60) and negative (-60) values are correspond with yellow and blue, respectively.

The photocatalytic activity of the samples was assessed from the decomposition of methylene blue using $365 \mathrm{~nm}$ irradiation ${ }^{11-13}$. A $0.01 \mathrm{~g}$ portion of the sample was placed in $4 \mathrm{~mL}$ of methylene blue solution $\left(1.0 \times 10^{-5} \mathrm{~mol} \cdot \mathrm{L}^{-1}\right)$ and this solution was then irradiated. The decrease in the absorption at about $660 \mathrm{~nm}$ was monitored over the course of 120 min. Furthermore, the oxidation catalytic activity of the samples was estimated with ascorbic acid solution. A $0.05 \mathrm{~g}$ of sample was put into $4 \mathrm{~mL}$ of $0.01 \mathrm{~mol} / \mathrm{L}$ of ascorbic acid solution. The color of the solution changes to brown by oxidation catalyst.

As the smoothness of sample powders, the static friction resistances were estimated on artificial leather with Portable Friction Meter 94i-II (SHINTO Scientific Co., Ltd., Tokyo, Japan). The sample powders were spread on the leather, and then a sensor was run over the powders.

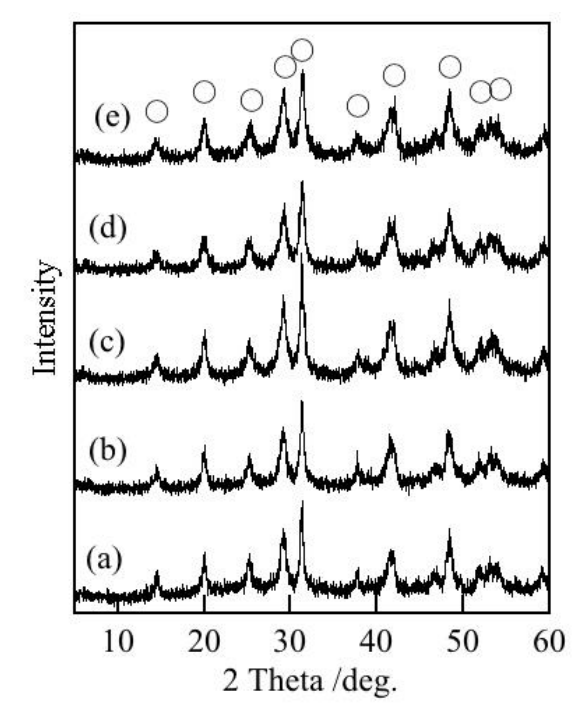

FIGURE 1 XRD patterns of samples prepared at various $\mathrm{pH}$ values, (a) 1, (b) 4, (c) 5, (d) 6, and (e) 7, $\bigcirc$; $\mathrm{CePO}_{4} \bullet \mathrm{nH}_{2} \mathrm{O}$.

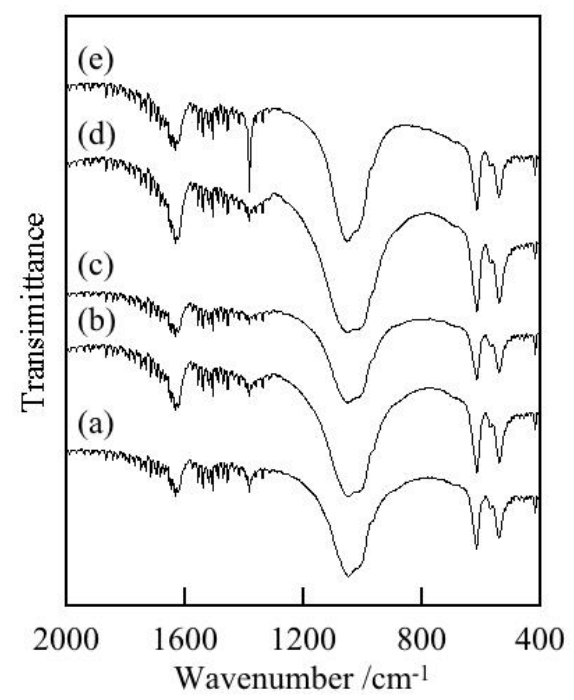

FIGURE 2 IR spectra of samples prepared at various $\mathrm{pH}$ values, (a) 1, (b) 4, (c) 5, (d) 6, and (e) 7 .

\section{RESULTS AND DISCUSSION}

Chemical composition and powder properties of cerium phosphates

Figure 1 shows the XRD patterns of the samples prepared at various $\mathrm{pH}$ values. All samples prepared in this work indicated the peaks of cerium phosphate hydrate. Sample prepared at pH 5 had stronger peaks than others. Figure 2 shows IR spectra of the samples prepared at various $\mathrm{pH}$ values. The peaks at 1050, 620 , and $540 \mathrm{~cm}^{-1}$ were attributed to phosphate anions ${ }^{14}$. The peak at $1630 \mathrm{~cm}^{-1}$ was attributed to the 

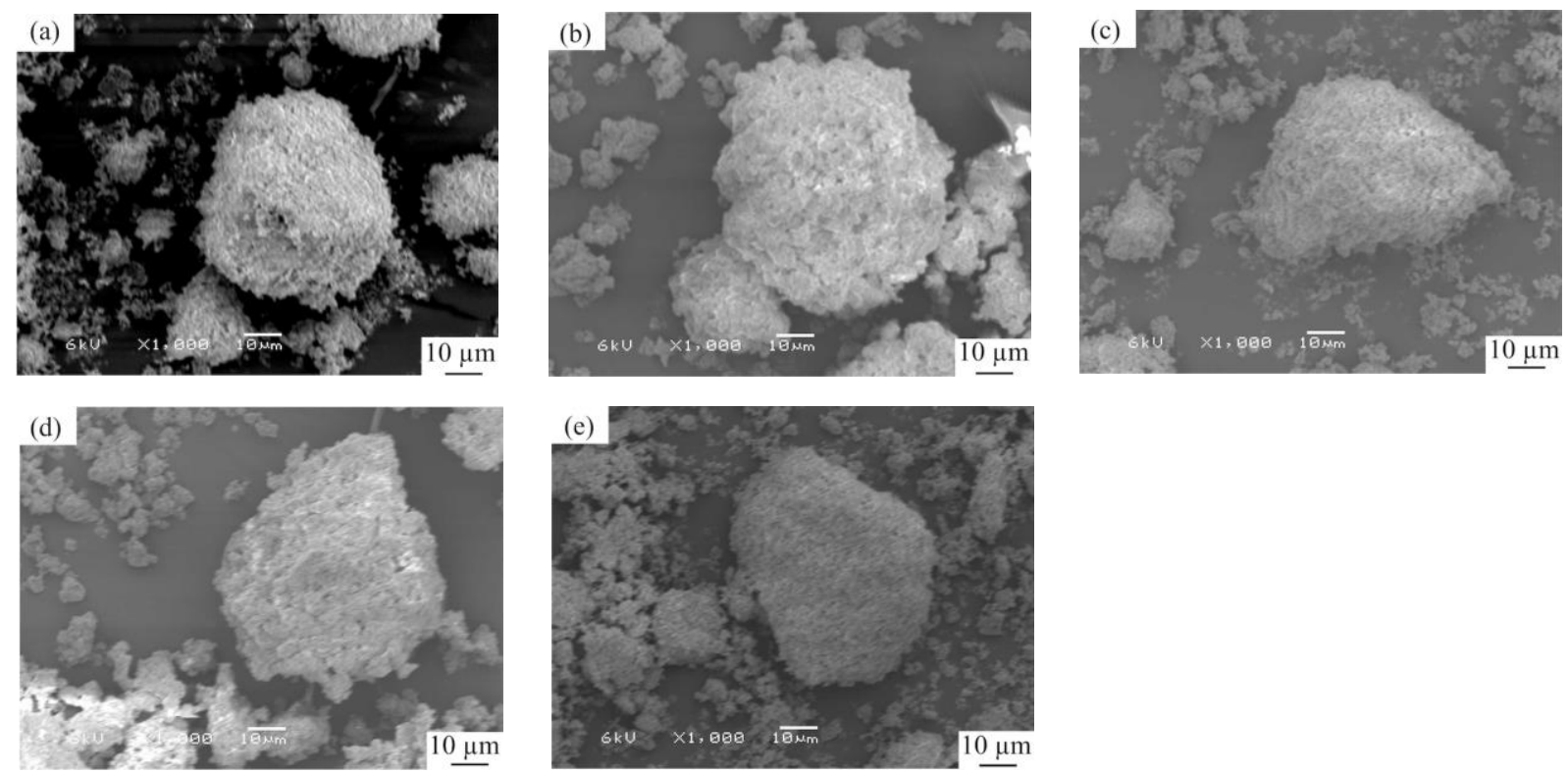

FIGURE 3 SEM images of samples prepared at various pH values, (a) 1, (b) 4, (c) 5, (d) 6, and (e) 7.

water of crystallization. The peak at $1380 \mathrm{~cm}^{-1}$ in spectra of sample prepared at $\mathrm{pH} 7$ was attributed to nitrate anion.

Spherical morphology of the particles is desirable for cosmetic applications ${ }^{15,16}$. Figure 3 shows representative SEM images of the samples prepared in various conditions. All samples prepared in this work had large particles and no specified shape. Small and homogeneous particles are suitable for cosmetic applications. However, overly small particles have a major shortcoming in that they enter the pores of the $\operatorname{skin}^{3}$. Generally, pigments with sub-micrometer dimensions are used in cosmetics. The standard size of white pigment particles used in cosmetics is difficult to determine because the size of the pores in skin is affected by factors such as age, gender, and climate. Furthermore, overly large particles are inappropriate for cosmetic purposes owing to cracking of their coating on the skin. It is therefore important to control the particle sizes of the pigment. Figure 4 shows the particle size distribution of the samples prepared in various conditions. All samples prepared in this study had a large amount of particles with dimensions of over $1 \mu \mathrm{m}$. Sample prepared at $\mathrm{pH} 5$ had relatively large particles, on the other hand, sample prepared at $\mathrm{pH} 4$ had relatively small particles.

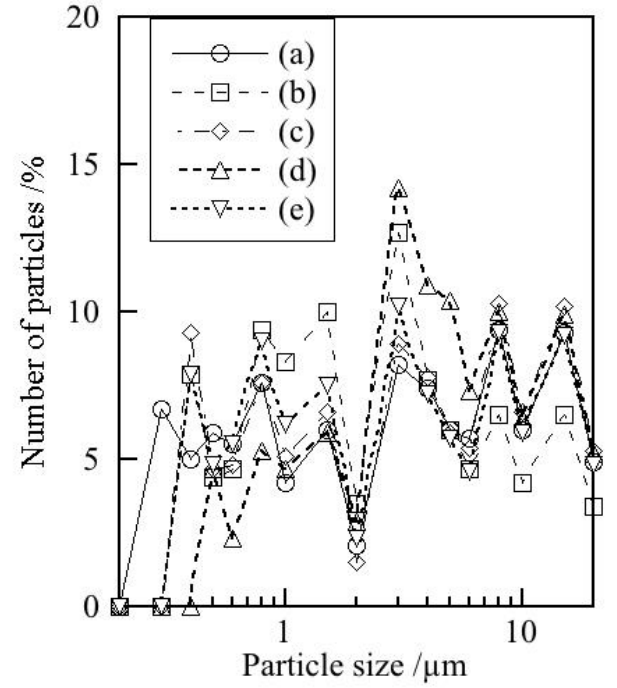

FIGURE 4 Particle size distribution of samples prepared at various $\mathrm{pH}$ values, (a) 1 , (b) 4, (c) 5 , (d) 6 , and (e) 7 .

\section{Cosmetic properties of cerium phosphates}

Figure 5 shows the UV-Vis reflectance spectra of the cerium phosphate prepared in various $\mathrm{pH}$ values. The sample prepared without $\mathrm{pH}$ adjustment indicated a little lower reflectance than others. The samples prepared at $\mathrm{pH} 5$ and 6 indicated high reflectance within the range of visible light. The color of sample powder was also estimated by $\mathrm{L}^{*} \mathrm{a} * \mathrm{~b} *$ color space. Table 1 shows the $\mathrm{L}^{*} \mathrm{a} * \mathrm{~b} *$ values of the samples prepared at various $\mathrm{pH}$ values. All samples had enough small $a^{*}$ and $b^{*}$ values, therefore the obtained samples were color-less powders. The samples prepared at $\mathrm{pH} \mathrm{4,5,6}$ indicated higher $\mathrm{L}^{*}$ 
values. These results were suitable as white pigments. The sample prepared without $\mathrm{pH}$ adjustment indicated a little lower $\mathrm{L}^{*}$ and large $\mathrm{b}^{*}$ values, which is related with a small amount of cerium $(+\mathrm{IV})$ cation.

Figure 6 summarizes the respective photocatalytic activities of the samples prepared in various conditions. Zinc oxide, which is widely used as a white pigment in cosmetics, was evaluated for comparison with cerium phosphate ${ }^{1}$. Methylene blue decomposed under UV irradiation in the presence of zinc oxide (Fig. 6(b)). Cerium dioxide and the samples prepared without $\mathrm{pH}$ adjustment and at $\mathrm{pH} 4$ indicated small decrease in residual ratio by the adsorption of methylene blue (Fig. 6(c)-(e)). However, the samples prepared at $\mathrm{pH} 5,6$, and 7 had no photocatalytic activity (Fig. 6(f)-(h)).

Since cerium dioxide works as an oxidation catalyst, the catalytic activity of the samples was estimated with ascorbic acid solution. Cerium dioxide changed the color of ascorbic acid solution to brown, however, samples prepared in this work produced white dispersed solutions without color-change. The cerium phosphate had no oxidation catalytic activity.

As described above, pigments with a high level of smoothness spread well across the skin, and powder smoothness is another important factor for cosmetic applications ${ }^{17}$. The static friction resistance of the samples prepared in various conditions was shown in Table 1 . The value of cerium dioxide was 0.398 . Sample prepared at $\mathrm{pH}$ 4 indicated lower resistance, however, sample prepared at $\mathrm{pH} 7$ had higher resistance. Samples prepared at $\mathrm{pH}$ 1-6 were suitable to use as a white pigment.

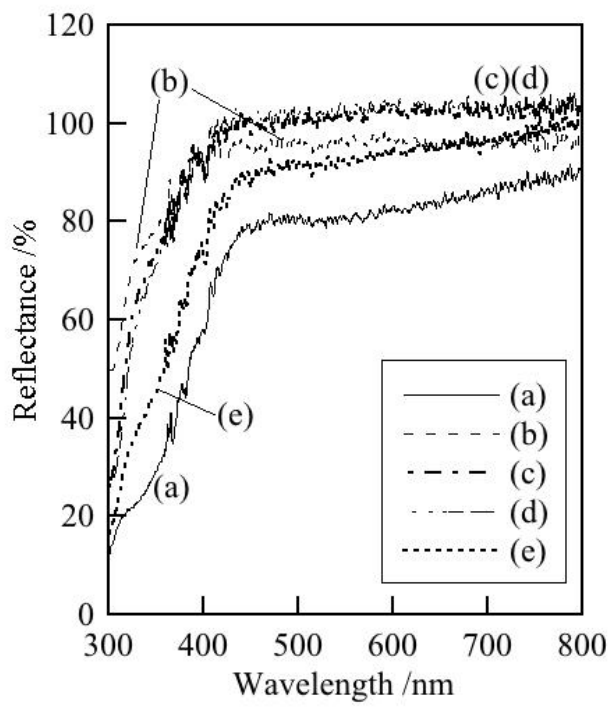

FIGURE 5 UV-Vis reflectance of samples prepared at various $\mathrm{pH}$ values, (a) 1, (b) 4, (c) 5, (d) 6, and (e) 7 .

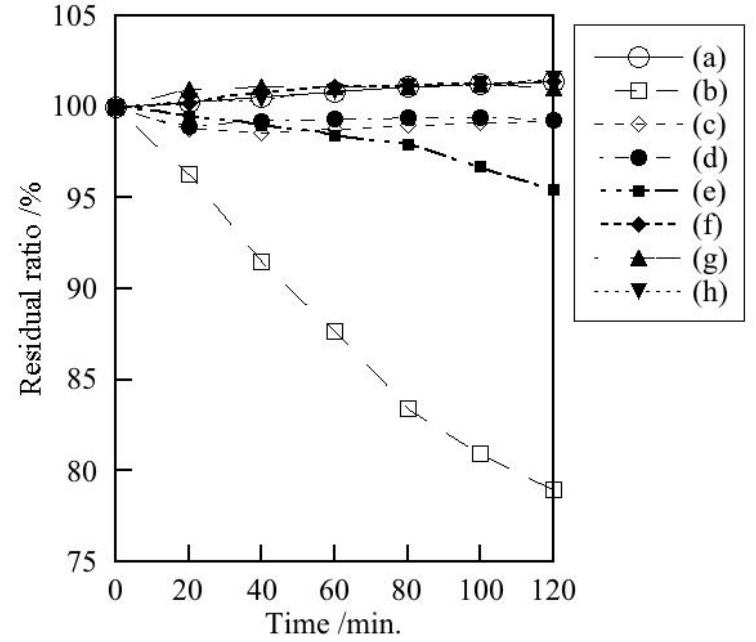

FIGURE 6 Photocatalytic activity of samples prepared at various $\mathrm{pH}$ values, (a) blank, (b) $\mathrm{ZnO}$, (c) $\mathrm{CeO}_{2}$, (d) 1, (e) 4, (f) 5, (g) 6, and (h) 7 .

TABLE 1 L*a*b* values and static friction resistances of samples prepared at various $\mathrm{pH}$ values

\begin{tabular}{ccrrc}
\hline $\mathrm{pH}$ & $\mathrm{L}^{*}$ & $\mathrm{a}^{*}$ & $\mathrm{~b}^{*}$ & $\begin{array}{c}\text { Resistance } \\
/-\end{array}$ \\
\hline 1 & 80.15 & 0.47 & 3.09 & 0.376 \\
4 & 97.30 & -0.28 & -0.32 & 0.304 \\
5 & 97.23 & -0.26 & -0.18 & 0.388 \\
6 & 95.32 & -1.46 & 0.07 & 0.398 \\
7 & 90.66 & -0.24 & 1.60 & 0.469 \\
\hline
\end{tabular}

\section{CONCLUSION}

The cerium phosphate was prepared at various $\mathrm{pH}$ values. All samples prepared in this work indicated XRD pattern of the cerium phosphate hydrate. These samples had large particles and no specified shape. The sample prepared at $\mathrm{pH} 4$ had relatively small particles and low static friction

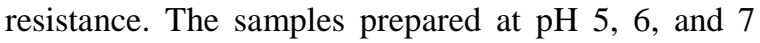
had no photocatalytic activity. The samples prepared at $\mathrm{pH} 5$ and 6 exhibited high reflectance within the range of visible light. The suitable condition was $\mathrm{pH}$ 5 and 6 to obtain the cerium phosphate white pigment from the viewpoints of whiteness, photocatalytic activity, and smoothness.

\section{REFERENCES}

1. N. A. Monteiro-Riviere, K. Wiench, R. Landsiedel, 
S. Schulte, A. O. Inman, J. E. Riviere, Toxicol. Sci., 123(1), 264-280 (2011).

2. J. Kockler, M. Oelgemöller, S. Robertson, B. D. Glass, Cosmetics, 1, 128-139 (2014).

3. K. Girigoswami, M. Viswanathan, R. Murugesan, A. Girigoswami, Mater. Sci. Eng. C, 56(1), 501-510 (2015).

4. H. Onoda, T. Yamaguchi, J. Mater. Chem., 22(37), 19826-19830 (2012).

5. H. Onoda, M. Haruki, T. Toyama, Ceram. Intern., 40(2), 3433-3438 (2014).

6. A. Davo-Quinonero, M. Navlani-Garcia, D. Lozano-Castello, A. Bueno-Lopez, J. A. Anderson, ACS catalysis, 6, 1723-1731 (2016).

7. G. Lafaye, J. Barbier Jr., D. Duprez, Catalysis Today, 253, 89-98 (2015).

8. A. Jain, A. M. Shore, S. C. Jonnalagadda, K. V. Ramanujachary, A. Mugweru, Appl. Catal., 489, 72-76 (2015).

9. Y. Cai, S. Feng, C. Ming, X. Ren, Y. Qin, L. An,
Resul. Phys., 6, 826-828 (2016).

10. G. V. Rao, H. D. Shashikala, J. Non-cryst. Solids, 402(15), 204-209 (2014).

11. J. S. Lee, W. L. Murphy, Adv. Mater., 25(8), 1173-1179 (2013).

12. S. Hiromoto, M. Inoue, T. Taguchi, M. Yamane, N. Ohts, Acta Biomater., 11(1), 520-530 (2015).

13. Z. Radovanovic, B. Jokic, D. Veijovic, S. Dimitrijevic, V. Kojic, R. Petrovic, D. Janackovic, App. Surf. Sci., 307(15), 513-519 (2014).

14. I. Lopes-Heras, Y. Madrid, C. Camara, Talanta, 124(15), 71-78 (2014).

15. T. Goto, S. Yin, T. Sato, T. Tanaka, Intern. J. Nanotechnol., 10(1-2), 48-56 (2013).

16. C. Su, H. Tang, K. Chu, C. Lin, Ceram. Int., 40(5), 6903-6911 (2014).

17. L. Xianjuan, X. Haiquan, C. Jing, S. Juncai, Y. Yuxiang, L. Xiangnong, Glass Phys. Chem., 37(3), 330-342 (2011). 